\title{
Effect of Co-administration Rotenone and Crocin on Biochemical and Histopathological Changes in Rat's Kidney
}

\author{
Amin Maghamifar ${ }^{1}$, Hossein Najafzadehvarziं ${ }^{2, *}$, Seyedmohammad Hossaini ${ }^{3}$ \\ 'Educated from School of Pharmacy, Islamic Azad University, Ayatollah Amoli Branch, Amol, IRAN. \\ ${ }^{2}$ Cellular and Molecular Biology Research Centre, Health Research Institute, Babol University of Medical Sciences, Babol, IRAN. \\ ${ }^{3}$ School of Veterinary Medicine, Islamic Azad University, Babol Branch, Babol, IRAN.
}

\begin{abstract}
Background: Rotenone is one of the most widely used pesticides in agriculture and may affect public health through the food chain. A possible mechanism of rotenone toxicity is oxidative stress. This study, the supportive effect of crocin (a substance derived from saffron) as an antioxidant on the renal toxicity of rotenone in an experimental animal model was investigated. Methods: First, male rats were divided into 4 groups (6 in each group) and received saline, crocin, rotenone and rotenone-crocin combination intraperitoneally for 10 days, respectively. Blood and kidney tissue samples were then isolated and biochemical factors including creatinine, nitrogen blood urea (BUN), sodium, potassium, Malondialdehyde and catalase were measured. The kidneys were examined histopathologically with a light microscope. Results: The results showed that rotenone caused damage to kidney tissue, which was observed in the form of vacuole degeneration, hyperemia and influx of inflammatory cells.
\end{abstract}

Crocin has also been shown to reduce the severity of rotenone-induced kidney damage. Also results showed that biochemical changes were not statistically significant between the groups. Conclusions: the crocin has protective influence on histopathological changes in rat's kidney following rotenone administration.

Key words: Crocin, Rotenone, Renal histopathology, Rats, Biochemical factors.

\section{Correspondence}

Hossein Najafzadehvarzi

Cellular and Molecular Biology Research Centre, Health Research Institute, Babol University of Medical Sciences, Babol, IRAN.

Phone no: +989166182496

Email: najafzadehvarzi@gmail.com

DOI: 10.5530/ijpi.2021.1.20

\section{INTRODUCTION}

Rotenone is a natural insecticide with high fat solubility and can easily cross the blood-brain barrier. This toxin inhibits complex 1 in the electron transport chain in the mitochondria. ${ }^{1}$ Some researchers showed that dopaminergic neurons in the brain are sensitive to this toxin and prolonged exposure of mice to rotenone could damages dopaminergic neurons and impairs their movement. ${ }^{2}$ Jiang et al. showed that rotenone can cause kidney toxicity. This compound causes histopathological changes in renal tissue including edema, tubular dilatation, glomerular damage and glomerular epithelium atrophy. ${ }^{3}$ Rotenone has also been shown to alter oxidative stress factors and antioxidant defence enzymes in the kidney. ${ }^{4}$ Crocin is one of the most important active components of saffron and the colour of saffron is due to the presence of this compound. Previous studies have shown that saffron extract has many properties such as antimicrobial, anticonvulsant, anti-inflammatory, anti-tumor, analgesic and antioxidant properties ${ }^{5}$ and has also been shown to be effective in preventing colorectal cancer. ${ }^{6}$ Crocin reduces colon inflammation by acting on the NF- $\kappa \beta$ signalling pathway. ${ }^{7}$ Crocin has a protective role in diabetes and reduction of renal complications and reduces serum levels of glucose, urea and creatinine in diabetic rats. ${ }^{8}$ According to a study by Hosseinzadeh et al. (2005), aqueous saffron extract improves oxidative damage due to ischemia and renal blood flow restoration in rats. ${ }^{9}$ Crocin acts as an antioxidant by removing free radicals and protects cells and tissues against oxidative stresses. ${ }^{10}$ Salahshour et al. (2016) reported that crocin can prevent morphineinduced liver toxicity as an antioxidant agent. ${ }^{11}$ Therefore, in this study, the supportive effect of crocin as an antioxidant on the renal toxicity of rotenone in an experimental animal model was investigated.

\section{MATERIALS AND METHODS}

The study protocol, designed according to the National Guidelines for Laboratory Animal Welfare and the European Economic Community Guidelines for the care and use of laboratory animals (EEC Directive of 1986; 86/609/EEC), was approved by the Ethics Committee of Babol University of Medical Sciences (approval number: IR. MUBABOL. REC. 1397.015). The smallest possible number of animals was recruited and the depth of anaesthesia was constantly monitored during the surgery to prevent any response to painful stimuli. Euthanasia was conducted through deep anaesthesia with Ketamine-Xylazine solution. The animals were kept at a constant temperature of $25^{\circ} \mathrm{C}$, humidity of $55 \%$ at $8: 00-$ 20:00 h light and 20:00 - 8:00 h dark cycle. The animals were fed standard chow until time of sacrifice.

Male Wistar rats (200-250 g) were obtained from Babol University of Medical Sciences and the randomly divided into 4 groups, each group consisting of 6 rats. Group 1 received saline, group 2 received crocin, group 3 received rotenone and group 4 received crocin and rotenone intraperitoneally (IP) for 10 days. The doses of crocin and rotenone were $50 \mathrm{mg} / \mathrm{kg}$ and $2 \mathrm{mg} / \mathrm{kg}$, respectively.

One day after the last injections and in accordance with the ethics of working with animals, the rats were first anesthetized with KetamineXylazine and blood was drawn from their hearts. A longitudinal incision was then made in the linea alba and their kidneys were isolated and homogenized in phosphate buffer. Part of rat kidney in each group is placed in $10 \%$ formalin to prepare pathological sections. For this purpose, the fixed kidney tissues were embedded in paraffin and $5-\mu \mathrm{m}$ thick sections were obtained using a microtome. Sections were subjected to staining with $\mathrm{H} \& \mathrm{E}$ and pathological changes in kidney tissue were 
examined using a light microscope. In microscopic studies, pathological lesions in kidney tissue were identified and graded. Tissue damage such as vacuolation, necrosis, hyperemia and etc. were recorded in each slide in each group. The severity of pathologically observed lesions was scored. Determination of malondialdehyde concentration in serum and organ homogenates was performed using the method of thiobarbituric acid which measures MDA-reactive products as described by Todorova et al. ${ }^{12}$ Catalase activity was determined using spectrophotometric method designed by the Koroliuk et al. ${ }^{13}$ Briefly, $10 \mu \mathrm{L}$ of sample was incubated with $100 \mu \mathrm{mol} / \mathrm{mL}$ of $\mathrm{H}_{2} \mathrm{O}_{2}$ in $0.05 \mathrm{mmol} / \mathrm{L}$ Tris- $\mathrm{HCl}$ buffer, $\mathrm{pH}=7$ for $10 \mathrm{~min}$. The reaction was terminated using rapidly adding $50 \mu \mathrm{L}$ of $4 \%$ ammonium molybdate. Yellow complex of ammonium molybdate and $\mathrm{H}_{2} \mathrm{O}_{2}$ was measured at $410 \mathrm{~nm}$. Catalase activity was defined as the amount of enzyme required to decompose $1 \mu \mathrm{mol} \mathrm{H}_{2} \mathrm{O}_{2}$ per min.

The analysis of serum BUN and serum creatinine $(\mathrm{Cr})$, sodium and potassium levels was estimated by using diagnostic kits (ParsAzmoon kit, IRI) and an automatic analyser (Abbott, model Alcyon 300, USA).

\section{RESULTS}

\section{Biochemical parameters}

Figure 1 showed that the lowest amount of serum BUN was in the group receiving rotenone which is significantly different from the control group $(P<0.05)$ and the group receiving rotenone $+\operatorname{crocin}(P<0.01)$.

Figure 2 showed that creatinine concentration was not different significantly in the control and other groups. Also, it was observed that the amount of sodium and potassium elements

in the control, crocin, rotenone and crocin + rotenone groups were not significantly different $(p>0.05)$.

Comparison of mean malondialdehyde concentration (MDA) in the kidney homogenized tissue and serum showed that there are no significant difference between control group and other groups. Also, the same results were observed for kidney homogenized tissue and serum catalase enzyme activity (Figure 3).

\section{Histopathological analysis}

Histopathological examination of renal tissue showed that in the control group, the kidney structure is normal and glomeruli, proximal and distal tubules are normal shape and normal cells (Figure 4 Part A). With the use of crocin in the second group, no changes were observed in kidney tissue and a structure similar to the control group was seen (Figure 4 Part B). While injecting rotenone in the third group, tissue damages such as hyperemia, vacuolar degeneration, inflammatory cell infiltration were observed in the kidneys (Figure 4 Part C). In the fourth group, which received crocin and rotenone at the same time, the severity of rotenoneinduced tissue damage was lower and no infiltration of inflammatory cells was observed (Figure 4 Part D). The scour of histopathological changes is presented in Table 1.

Table 1: Pathological lesions observed in different groups.

\begin{tabular}{cccc}
\hline Groups & Hyperemia & $\begin{array}{c}\text { Vacuolar } \\
\text { degeneration }\end{array}$ & $\begin{array}{c}\text { Inflammatory } \\
\text { cell infiltration }\end{array}$ \\
\hline Control & -- & -- & -- \\
Crocin & -- & -- & -- \\
Rotenone & ++ & +++ & + \\
Crocin+Rotenone & + & ++ & -- \\
\hline
\end{tabular}

\section{DISCUSSION}

In the present study, the effect of crocin on changes in renal-related biochemical factors as well as histopathological changes in rat kidneys following intraperitoneal administration of rotenone and crocin (alone and in combination) were investigated. The serum biochemical analysis showed that there were no significant changes in creatinine, sodium and potassium and no significant changes were observed in the group receiving the rotenone along with the group receiving crocin. The reason for this can be various, one of which is the dose (amount and duration of toxin consumption) as well as genetic differences in mice. A study conducted by Jiang et al. (2017) stated that renal toxicity of rotenone is dose-dependent. While in histopathological examinations of kidney tissue, it was observed that rotenone can cause hyperemia, vacuolar degeneration and invasion of inflammatory cells. ${ }^{3}$ This indicates that the amount of toxin or its purity could change the tissue but could not change the function of the tissue, leading to biochemical changes.

Our results showed that by using crocin, the severity of tissue changes in the kidneys was reduced and at least no influx of inflammatory cells was observed which indicating the protective effect of crocin against rotenone-induced damage in the kidney tissue. Since rotenone could not cause functional damage to the kidneys, no changes were observed in the levels of oxidative stress factors, including Malondialdehyde concentration and catalase enzyme activity.

Jiang et al. (2017), suggested that rotenone alters oxidative stress and induced damage in the kidney tissues(3). In this study, rotenone at doses of 1,2 and $4 \mathrm{mg} / \mathrm{kg}$ was administered orally to mice for 28 days, while in our study, rotenone at a dose of $2 \mathrm{mg} / \mathrm{kg}$ was administered to mice intraperitoneally for 10 days. In the Jiang et al. experiment, rotenone at doses of 2 and $4 \mathrm{mg} / \mathrm{kg}$ significantly reduced the weight of mice and also increased creatinine and BUN and excreted protein and phosphate in the urine. Also were reported some histopathological changes, such as vacuolar degeneration and the influx of inflammatory cells in the kidney tissues following treatment with rotenone (3), which is consistent with the results of our studies. They also reported that rotenone can cause changes in antioxidant defence factors, including a significant reduction in superoxide dismutase and glutathione peroxidase at doses of 2 and 4 $\mathrm{mg} / \mathrm{kg}$ (3), while in our study, the dose of $2 \mathrm{mg} / \mathrm{kg}$ could not have any

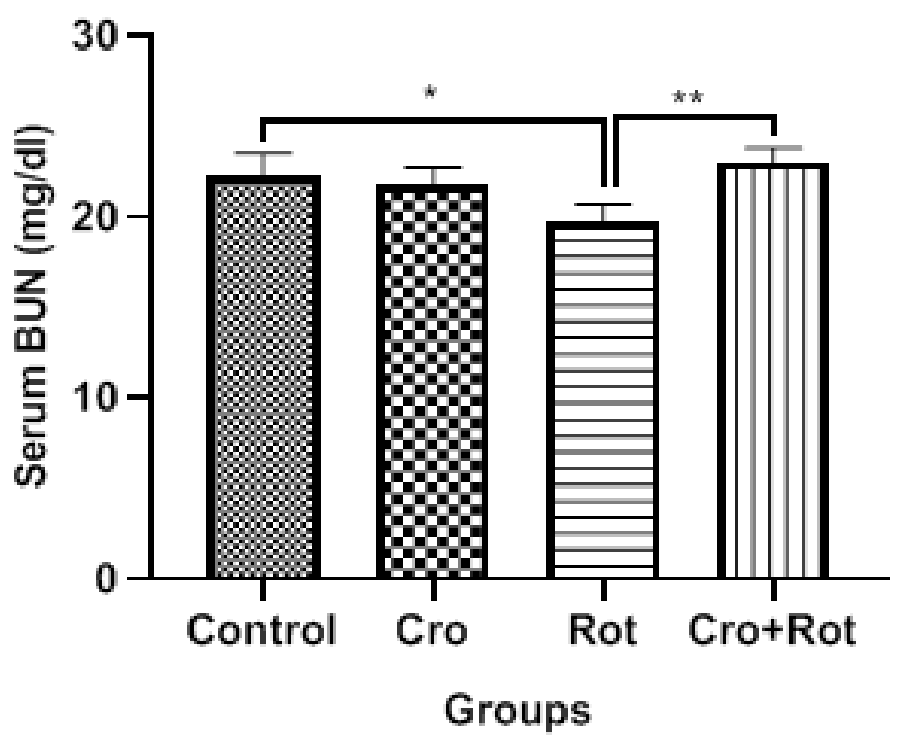

Figure 1: Results of serum BUN in the control, crocin, rotenone and crocin + rotenone groups. As shown the lowest amount of serum BUN was observed in the group receiving rotenone. 

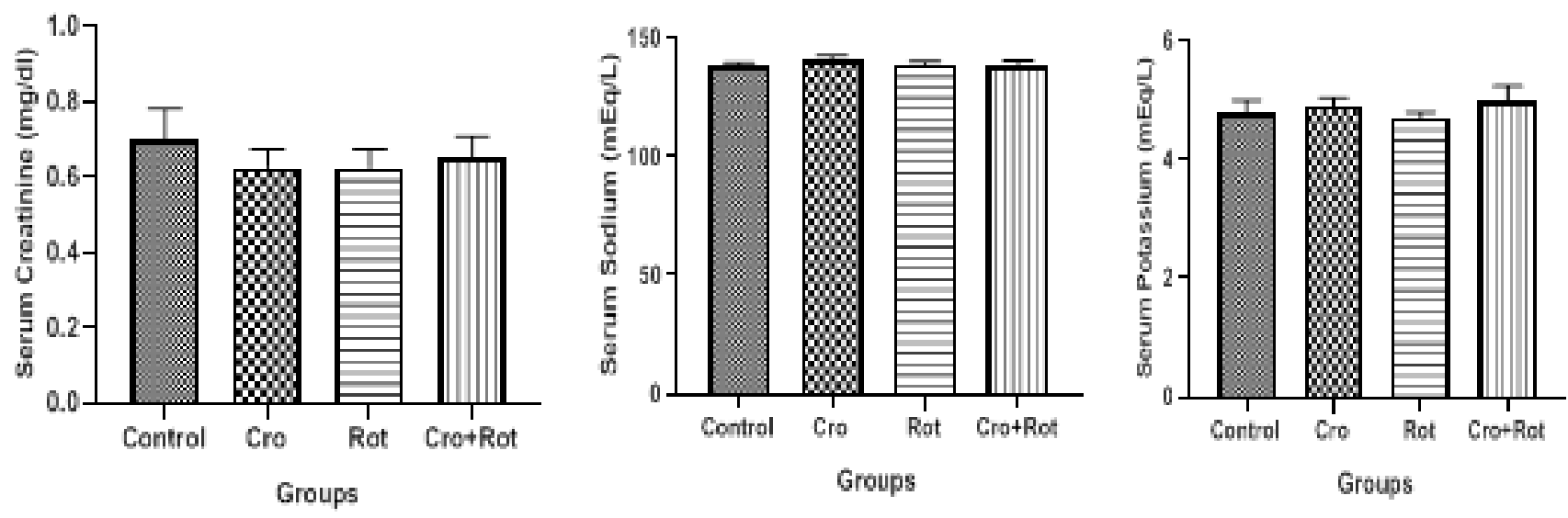

Figure 2: Serum creatinine, sodium and potassium in the control, crocin, rotenone and crocin+rotenone groups. No significant differences were observed in the control and other groups.
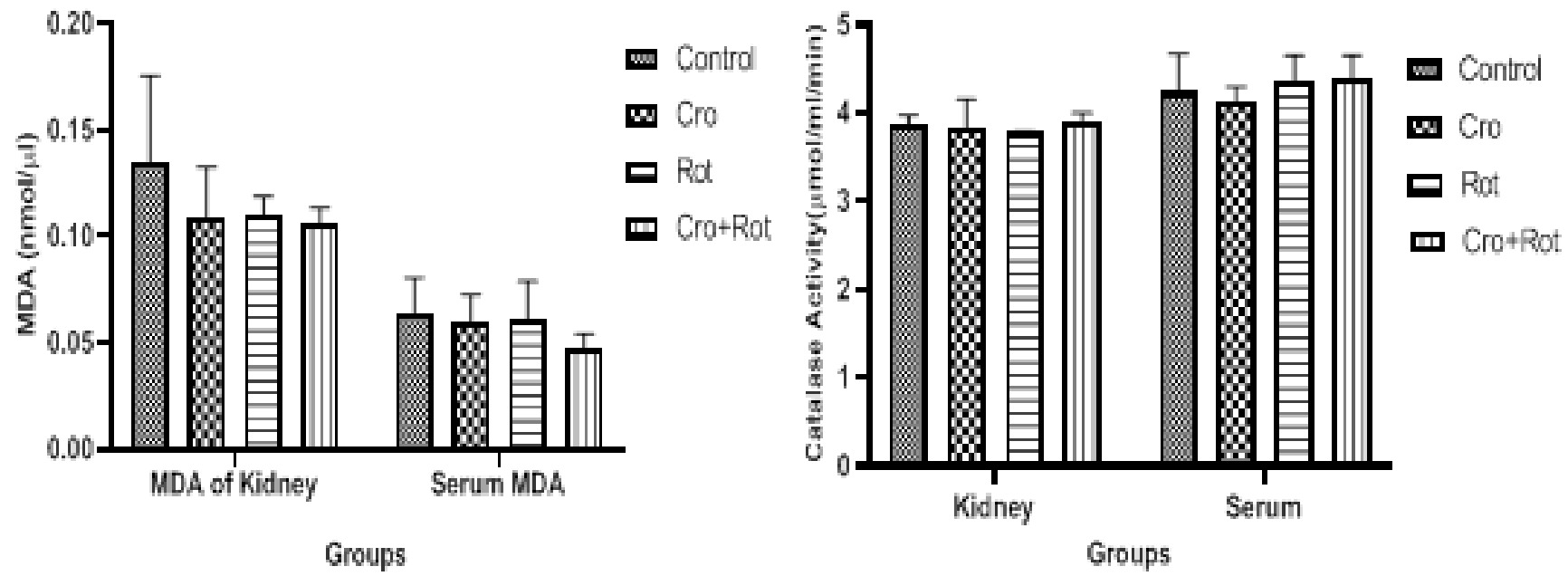

Figure 3: MDA concentration and catalase activity in the the kidney homogenized tissue and serum samples. Resuls showed that there were no significant difference between control and other groups.
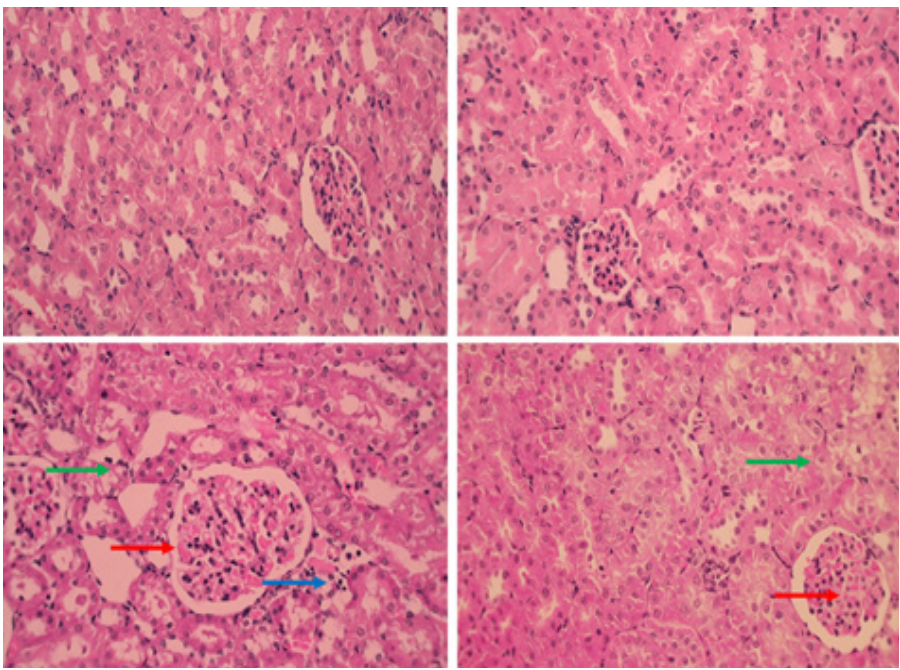

Figure 4: A: Control group, normal tissue, B: Crocin receiving group, normal tissue, C: Rotenone receiving group, hyperemia, vacuolar degeneration, inflammatory cell infiltration, D: Crocin and rotenone receiving group, hyperemia, vacuolar degeneration. H\&E staining. 40X. effect on antioxidant defence factors or oxidative stress. It is thought that the duration of toxin used in our study (10 days), was probably insufficient as compared to the Jiang et al. study (28 days).

In the Akinmoladun et al. (2018) study, treatment of rats with rotenone at a dose of $1.5 \mathrm{mg} / \mathrm{kg}$ for 10 days caused liver tissue damage. ${ }^{14}$ Tripathi et al. (2019) studied the oxidative stress induced by rotenone. They found that a significant alleviation in the levels of rotenone-induced pro-oxidant and anti-oxidant markers following exposure of metformin. They suggest that metformin supplementation shows a protective role in against rotenone-induced redox imbalance and cytotoxicity in rat erythrocytes. ${ }^{15}$ Rotenone is a potent mitochondrial toxin that blocks complex-1 in the mitochondrial electron chain. It also inhibits oxidative reductase, ubiquinone and $\mathrm{NADH}$, leading to the accumulation of large amounts of free radicals and reactive oxygen species and causing oxidative damage. ${ }^{16}$ Because of high metabolic status and many active enzymes in the Kidney tissue and also consuming a lot of oxygen, this tissue can be exposed to rotenone-induced damage. ${ }^{17}$ Radad et al. (2013) conducted a study for the short-term effects of rotenone on neural and non-neural tissues and they reported that subcutaneously administration of rotenone at a dose of $10 \mathrm{mg} / \mathrm{kg}$ for 7 days and also at a dose of $3 \mathrm{mg} /$ $\mathrm{kg}$ for 30 days can cause damage to neural and non-neural tissues; 
Including kidney tissue and also can cause interstitial haemorrhage. The researchers concluded that rotenone could damage tissues by damaging blood vessels. ${ }^{18}$ Abdel-Salam et al. (2019) subcutaneously administered rotenone $1.5 \mathrm{mg} / \mathrm{kg}$ three times a week for two weeks. They showed that rotenone can damage kidney tissue which in consistent with our result. ${ }^{4}$ Crown et al. (2019) investigated the protective effect of the 3 flavonoids catechin, quercetin and taxifolin on rotenone-induced renal impairment in rats. They showed that rotenone increased oxidative stress and impaired renal function. While these flavonoids reduced the effects of rotenone. Crown et al. also stated that rotenone caused changes in Malondialdehyde, carbonyl protein glutathione, FRAP score and activity of glutathione transferase, superoxide dismutase, xanthine oxidase, lactate and dehydrogenase enzymes. ${ }^{19}$ In our study, crocin was able to reduce the severity of rotenone-induced tissue damage in the kidneys. Crocin is a plant carotenoid with antioxidant properties that can counteract the mechanism of toxicity of rotenone, which damages mitochondria and increases oxidative stress. This important carotenoid has a protective effect against some plant and metal toxins for various tissues. Some of these studies mentioned the protective effect of crocin in kidney tissues. For example, Bandegi et al. (2014) investigated the effect of crocin and saffron extract on kidney protection in mice under chronic stress and showed that these two compounds can prevent kidney damage with antioxidant properties..$^{20}$ Jalili et al. (2020) investigated the protective effect of crocin on methotrexate induced-renal toxicity. They found that crocin methotroxate caused oxidative stress that damaged the kidneys and crocin with antioxidant effect reduced this complication. ${ }^{21}$ Naghizadeh et al. (2010) investigated the protective effect of crocin against cisplatin-induced toxicity in rats by administering high doses of crocin (100, 200 and $400 \mathrm{mg} / \mathrm{kg}$ ) for 4 consecutive days. They observed that crocin could significantly reduce MDA and increase glutathione peroxidase levels and reduced cisplatin toxicity to the kidneys. ${ }^{19,22}$ Lai et al. (2020) reported the combination crocin and quercetin can more significantly improve renal fibrosis in high-fat diet- and streptozotocininduced type 2 diabetes. ${ }^{23}$ Ajami et al. (2010) evaluated the protective effect of saffron against gentamicin-induced renal toxicity in rats. Saffron was able to neutralize the effects of gentamicin on the kidney so that the amount of creatinine and BUN was reduced and also the amount of MDA and tissue damage was reduced significantly. ${ }^{24}$ Yarjani et al. (2017) showed that administration of $100 \mathrm{mg} / \mathrm{kg}$ crocin intraperitoneally for 7 days reduced the toxic effects of gentamicin in renal tissue. This protective effect of crocin is related to its antioxidant properties, which prevent the production of reactive oxygen species, prevent DNA breakage and ultimately prevent cell necrosis. ${ }^{25}$ Some studies have shown that crocin also has anti-inflammatory properties, as Nam et al. (2010) showed that crocin prevents the release of TNF- $\alpha$ and IL- $\beta$ cytokines and the activation of NF-K $\beta$ protein. Therefore, the pharmacological effects of crocin are important from both antioxidant and anti-inflammatory aspects. $^{26}$

\section{CONCLUSION}

In the present study, rotenone was administered intraperitoneally at a dose of $2 \mathrm{mg} / \mathrm{kg}$ for 10 days at the tissue level and was able to damage the kidneys, although this damage did not occur biochemically. While crocin consumption was able to reduce the pathological effects of rotenone on the kidneys.

\section{ACKNOWLEDGEMENT}

We appreciated the Islamic Azad University, Amoli Branch for supporting this study.

\section{CONFLICT OF INTEREST}

The authors declare that there are no conflicts of interest.

\section{ABBREVIATIONS}

ANOVA: One-way variance analysis; BUN: nitrogen blood urea; i.p: Intraperitoneally; LSD: Least statistical differences; S.E.M: Standard error of the mean.

\section{REFERENCES}

1. Talpade DJ, Greene JG, JrHiggins DS, Greenamyre JT. In vivo labelling of mitochondrial complex i (nadh: Ubiquinoneoxidoreductase) in rat brain using [3h] dihydrorotenone. J Neurochem. 2000;75(6):2611-21.

2. Deng YT, Huang HC, Lin JK. Rotenone induces apoptosis in MCF-7 human breast cancer cell-mediated ROS through JNK and p38 signaling. Molecular Carcinogenesis: Published in cooperation with the University of Texas MD Anderson Cancer Center. 2010;49(2):141-51.

3. Jiang XW, Qiao L, Feng XX, Liu L, Wei OW, et al. Rotenone induces nephrotoxicity in rats: oxidative damage and apoptosis. Toxicol Mech Methods. 2017;27(7):528-36.

4. Abdel-Salam OM, Youness ER, Ahmed NA, El-Toumy SA, Souleman AM, Shaffie $\mathrm{N}$, et al. Bougainvillea spectabilis flowers extract protects against the rotenoneinduced toxicity. Asian Pac J Trop Med. 2017;10(5):478-90.

5. Ghadrdoost B, Vafaei AA, Rashidy-Pour A, Hajisoltani R, Bandegi AR, Motamedi $F$, et al. Protective effects of saffron extract and its active constituent crocin against oxidative stress and spatial learning and memory deficits induced by chronic stress in rats. Eur J Pharmacol. 2011;667(1-3):222-9.

6. Aung $\mathrm{HH}$, Wang CZ, Ni M, Fishbein A, Mehendale SR, Xie JT, et al. Crocin from Crocus sativus possesses significant anti-proliferation effects on human colorectal cancer cells. Exp Oncol. 2007;29(3):175.

7. Rezaei N, Avan A, Hassanian-Mehr SM, Khazaei M. Effect of Crocin on Inflammatory Bowel Diseases. J Isfahan Med School. 2017;34(414):1640-7.

8. Samadi $\mathrm{H}$, Javadi $\mathrm{SH}$, Asri $\mathrm{S}$. Evaluation of the effects of crocin on the serum levels of glucose, insulin, urea, creatinine and $\beta 2 \mathrm{~m}$ in healthy and streptozotocininduced diabetic rats. J Urmia University Med Sci. 2015;26(9):802-12.

9. Hosseinzadeh H, Sadeghnia HR, Ziaee T, Danaee A. Protective effect of aqueous saffron extract (Crocus sativus L.) and crocin, its active constituent, on renal ischemia-reperfusion-induced oxidative damage in rats. J Pharm Pharm Sci. 2005;8(3):387-93

10. Melnyk JP, Wang S, Marcone MF. Chemical and biological properties of the world's most expensive spice: Saffron. Food Research International. 2010;43(8):1981-9.

11. Salahshoor MR. Protective effect of crocin on liver toxicity induced by morphine. Res Pharm Sci. 2016;11(2):120.

12. Todorova I, Simeonova G, Kyuchukova D, Dinev D, Gadjeva V. Reference values of oxidative stress parameters (MDA, SOD, CAT) in dogs and cats. Comparative Clin Pathol. 2005;13(4):190-4.

13. Koroliuk MA, Ivanova LI, Maiorova IG, Tokarev VE. Methods of catalase activity determining. Laboratornoe Delo. 1988;1:16-9.

14. Akinmoladun AC, Oladejo CO, Josiah SS, Famusiwa CD, Ojo OB, Olaleye MT. Catechin, quercetin and taxifolin improve redox and biochemical imbalances in rotenone-induced hepatocellular dysfunction: Relevance for therapy in pesticide-induced liver toxicity?. Pathophysiology. 2018;25(4):365-71.

15. Tripathi SS, Singh AK, Akhtar F, Chaudhary A, Rizvi SI. Metformin protects red blood cells against rotenone induced oxidative stress and cytotoxicity. Arch Physiol Biochem. 2019;1-10.

16. Bonet-Ponce L, Saez-Atienzar S, DaCasa C, Sancho-Pelluz J, Barcia JM Martinez-Gil N, et al. Rotenone induces the formation of 4-hydroxynonenal aggresomes. Role of ROS-mediated tubulin hyperacetylation and autophagic flux disruption. Mol Neurobiol. 2016;53(9):6194-208.

17. Meng $\mathrm{QH}$, Liu HB, Wang JB. Polydatin ameliorates renal ischemia/reperfusion injury by decreasing apoptosis and oxidative stress through activating sonic hedgehog signaling pathway. Food Chem Toxicol. 2016;96:215-25.

18. Radad K, Hassanein K, Moldzio R, Rausch WD. Vascular damage mediates neuronal and non-neuronal pathology following short and long-term rotenone administration in Sprague-Dawley rats. Experimental and Toxicol Pathol. 2013;65(1-2):41-7.

19. Crown OO, Ogundele OO, Akinmoladun AC, Famusiwa CD, Josiah SS, Olaleye MT, et al. Effects of catechin, quercetin and taxifolin on redox parameters and metabolites linked with renal health in rotenone-toxified rats. Niger J Physiol Sci. 2019;34(1):1-0.

20. Bandegi AR, Rashidy-Pour A, Vafaei AA, Ghadrdoost B. Protective effects of Crocus sativus $\mathrm{L}$. extract and crocin against chronic-stress induced oxidative damage of brain, liver and kidneys in rats. Adv Pharm Bull. 2014;4(Suppl 2):493.

21. Jalili C, Ghanbari A, Roshankhah S, Salahshoor MR. Toxic Effects of Methotrexate 
on Rat Kidney Recovered by Crocin as a Consequence of Antioxidant Activity and Lipid Peroxidation Prevention. Iran Biomed J. 2020;24(1):39-46.

22. Naghizadeh B, Mansouri SM, Mashhadian NV. Crocin attenuates cisplatininduced renal oxidative stress in rats. Food Chem Toxicol. 2010;48(10):2650-5.

23. Lai LL, Lu HO, LiWN, Huang HP, Zhou HY, Leng EN, et al. Protective effects of quercetin and crocin in the kidneys and liver of obese Sprague-Dawley rats with Type 2 diabetes: Effects of quercetin and crocin on T2DM rats. Hum Exp Toxicol. 2020;960327120954521.
24. Ajami M, Eghtesadi S, Pazoki-Toroudi H, Habibey R, Ebrahimi SA. Effect of crocus sativus on gentamicin induced nephrotoxicity. Biol Res. 2010;43(1):83 90.

25. Yarijani ZM, Pourmotabbed A, Pourmotabbed T, Najafi H. Crocin has antiinflammatory and protective effects in ischemia-reperfusion induced renal injuries. Iran J Basic Med Sci. 2017;20(7):753.

26. Nam KN, Park YM, Jung HJ, Lee JY, Min BD, Park SU, et al. Anti-inflammatory effects of crocin and crocetin in rat brain microglial cells. Eur J Pharmacol. 2010;648(1-3):110-6.

Article History: Submission Date : 12-09-2020; Revised Date : 11-10-2020; Acceptance Date : 19-12-2020

Cite this article: Maghamifar A, Najafzadehvarzi H, Hossaini S. The Effect of Co-administration Rotenone and Crocin on Biochemical and Histopathological Changes in Rat's Kidney. Int. J. Pharm. Investigation. 2021;11(1):108-12. 